\begin{tabular}{|c|c|c|}
\hline Case Reports & \multicolumn{2}{|c|}{ Case Rep Gastroenterol 2016;10:181-192 } \\
\hline Gastro & $\begin{array}{l}\text { DOI: 10.1159/000445373 } \\
\text { Publisnea onine: Iviay } 19,2016\end{array}$ & $\begin{array}{l}\text { (C) } 2016 \text { The Author(s) } \\
\text { Published by S. Karger AG, Basel } \\
\text { www.karger.com/crg }\end{array}$ \\
\hline & \multicolumn{2}{|c|}{$\begin{array}{l}\text { This article is licensed under the Creative Commons Attribution-NonCommercial } 4.0 \\
\text { International License (CC BY-NC) (http://www.karger.com/Services/OpenAccessLicense). } \\
\text { Usage and distribution for commercial purposes requires written permission. }\end{array}$} \\
\hline
\end{tabular}

\title{
Lymphoepithelial Cyst of the Pancreas
}

\author{
Prabhu Arumugam $^{a} \quad$ Natalie Fletcher $^{a} \quad$ Charis Kyriakides $^{a} \quad$ Lisa Mears $^{b}$ \\ Hemant M. Kocher ${ }^{a}$ \\ ${ }^{a}$ Department of HPB Surgery, Barts and the London HPB Centre, Barts Health NHS Trust, \\ The Royal London Hospital, London, United Kingdom; 'D Department of HPB Pathology, \\ Barts and the London HPB Centre, Barts Health NHS Trust, The Royal London Hospital, \\ London, United Kingdom
}

\section{Keywords}

Benign cyst · Diagnosis · Surgery

\begin{abstract}
Lymphoepithelial cyst (LEC) of the pancreas is an extremely rare, benign pancreatic cystic lesion that is difficult to differentiate preoperatively from other cystic pancreatic lesions. LEC may have malignant potential. Here, we describe a case of LEC of the pancreas - initially suspected to be a mucinous cyst neoplasm - in an elderly man presenting with abdominal pain, who went on to have a distal pancreatectomy and splenectomy. We also review the relevant literature and discuss implications for the diagnosis and management of this rare lesion.
\end{abstract}

\section{Introduction}

Cystic lesions of the pancreas are relatively rare, and they are divided into true cysts, pseudocysts, and cystic neoplasms [1]. In adults, 85-90\% of these lesions are pseudocysts, and they usually occur as a complication of pancreatitis. True cysts are most often neoplastic. A true cyst is distinguished by the presence of an epithelial lining, indicating its benign natural history and developmental origin. 
Lymphoepithelial cysts (LECs) are very rare, non-malignant lesions which were first described by Lüchtrath and Schriefers in 1985 [2]. LECs are true pancreatic cysts that are lined by squamous epithelium and surrounded by mature lymphoid tissue. Kavuturu et al. [3] reported that in the 28 years since the first report of an LEC, 109 cases have so far been documented in the literature. Recent reviews documenting the demographic features of LECs indicate a strong male preponderance [4], with lesions of variable size distributed throughout the head, body, and tail of the pancreas [5]. Approximately half of the patients present incidentally, with the remaining patients being associated with non-specific symptoms such as nausea, vomiting, diarrhoea, abdominal pain, weight loss, and fatigue [3].

It has been thought to be difficult to differentiate LECs from other pancreatic lesions, such as serous cystic neoplasms, mucinous cystic neoplasms, and intraductal papillary mucinous neoplasms, because the appearance of the LEC on imaging varies from patient to patient and sometimes is similar to other pancreatic lesions [5]. LECs are benign and do not possess malignant potential, and, thus, an accurate identification of these lesions is important to avoid unnecessary intervention. The clinical and pathological features of LECs are not yet fully characterized. Herein, we report a case of LEC of the pancreas.

\section{Case Report}

A 79-year-old male presented with abdominal pain and early satiety. He had a past medical history of aortic valve replacement (requiring long-term warfarin therapy), sigmoid colectomy for diverticular disease, mild pulmonary fibrosis, transurethral resection of the prostate, excision of a benign right-sided parotid tumour, long-standing hiatus hernia, hypertension, and hypercholesterolemia. As part of his investigative workup he had an upper gastrointestinal endoscopy, which confirmed a diagnosis of hiatus hernia and tortuous oesophagus. Further, he underwent computed tomography (CT) imaging, which demonstrated an $8.6 \times 6.2 \mathrm{~cm}$ loculated cystic lesion in the tail of the pancreas, with no internal septa or enhancing components (fig. 1). There was no pancreatic duct dilatation, and no other intraabdominal abnormalities were noted (with the exception of the hiatus hernia). There was no prior history of pancreatitis, pancreatic insufficiency, or trauma. Endoscopic ultrasound (EUS) imaging was considered but was deemed unsuitable owing to the patient's tortuous oesophagus.

Percutaneous aspiration of the cyst and analysis of cyst fluid for cytology, carcinoembryonic antigen (CEA), and amylase were performed to further investigate the cystic lesion. Cytological analysis of the cyst fluid revealed abundant mucoid material with some inflammatory cells and a very occasional small group of cytologically benign glandular epithelial cells. No malignant cells were seen, but features were suggestive of a mucinous cyst. Fluid amylase was $196 \mathrm{U} / \mathrm{l}$, and fluid CEA was markedly elevated at 5,618.0 $\mu \mathrm{g} / \mathrm{l}$, which supported a diagnosis of mucinous cystic neoplasm. In light of this, surgical resection was advised. It should be noted that the patient was asymptomatic at the time of surgery.

At laparotomy, a cystic tumour was seen involving the distal pancreas and splenic hilum. The cyst was opened and drained, and cyst contents were sent for microscopy and culture, $\alpha$-fetoprotein - as the cyst fluid was caseous - and amylase, CEA, and cytological analysis. Due to dense adhesion of the cyst wall to the splenic vein, it was therefore necessary to perform distal pancreatectomy and splenectomy. A good resection margin was achieved. The patient had a good postoperative course with an uneventful recovery apart from a low- 
volume pancreatic leak. He was discharged on postoperative day 8 after re-instating his warfarin.

Macroscopic histopathological examination of the excised specimen found a thin-walled cyst (received opened) on the superior body of the pancreas that measured $50 \times 55 \times 8 \mathrm{~mm}$. The cyst was not found to communicate with the pancreatic duct. The cyst was multilocular with a wall thickness of $1 \mathrm{~mm}$. A nodular yellow lesion was seen attached to the lining of the cyst which measured $15 \times 18 \times 8 \mathrm{~mm}$. This nodule was soft to the touch and contained cream, soft, caseous material.

Microscopic analysis found the multilocular cystic lesion to be lined predominantly by keratinizing squamous epithelium, and the cysts were filled with keratin. Some areas of the epithelium appeared to have columnar morphology, and other areas showed evidence of sebaceous differentiation. No eccrine glands, apocrine glands, or hair follicles were identified. Beneath the epithelium, there was an associated lymphocytic infiltrate with lymphoid follicle formation. There was no evidence of epithelial atypia or malignancy. The lesion was diagnosed as an LEC (fig. 2). There was no significant histological abnormality seen in the adjacent pancreatic parenchyma or spleen.

\section{Discussion}

LECs of the pancreas are an extremely rare form of benign pancreatic cysts that account for approximately $0.5 \%$ of all pancreatic cysts [6]. The first case of LEC of the pancreas was described by Lüchtrath and Schriefers [2] in 1985, and, since then, over 100 cases have been documented in the literature [3]. Due to its rarity, it is a poorly characterized lesion, and its pathogenesis is not fully understood [6,7]. Aetiological theories that have been considered include formation from squamous metaplasia of the pancreatic ducts, derivation from epithelial remnants in lymph nodes, displacement of branchial cysts that go on to fuse with the pancreas during embryogenesis, or the possibility that LECs are a form of teratoma [6].

In order to summarize the clinical features of pancreatic LECs, an online literature search of PubMed was performed using the free text search term 'lymphoepithelial cyst pancreas', which yielded 117 results. Bibliographies were hand searched for relevance and articles, and detailing case reports were identified for inclusion in the literature review. Two key review articles by Adsay et al. [6] and Sewkani et al. [4] were identified that summarized a total of 92 cases from 1985 to 2010; the main findings of these review articles are summarized in table 1 . A further 21 articles [3, 7, 8, 9-26] were identified, which, including the current report, document a total of 56 cases that have been published since the review by Sewkani et al. [4] - features of these case reports were compiled and are summarized in table 2. Summarized findings of all 148 cases identified in our literature review, including the current case, are described in table 3.

Upon reviewing the world literature, several key features of LECs of the pancreas can be described. They occur predominantly in male patients (M:F ratio $=4: 1)$ with a mean age of 55 years, although a wide age range (20-82 years) has been documented [6, 7]. Abdominal pain or discomfort is the most common presenting symptom, although a high proportion of cases are asymptomatic or are diagnosed incidentally [4, 6, 7]. LECs tend to be well demarcated from surrounding pancreatic and adipose tissue and are commonly spherical with a well-defined wall [6]. Cases are often peripancreatic rather than intrapancreatic, and the cysts can be multilocular (60\%) or unilocular (40\%) [6]. LECs can range in size from 0.5 to

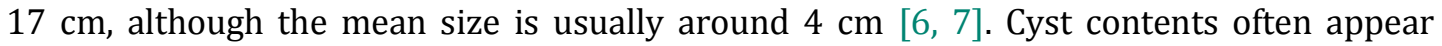


'cheesy' or caseous (indicative of keratinaceous debris), but can be clear or serous [6]. Microscopically, LECs are characteristically lined by stratified squamous epithelium with an adjacent subepithelial layer of lymphoid tissue containing lymphoid follicles. A small percentage of cases in the literature have shown sebaceous differentiation, and, occasionally, mucinous cells have been present [6]. LECs tend to occur with relatively equal frequency in the head, body, and tail of the pancreas [4, 6].

No recurrences or malignant progression of pancreatic LECs have been documented in the literature, suggesting it is an entirely benign lesion [7, 8]. Despite this, many cases are ultimately managed with surgical resection, as LECs are difficult to distinguish preoperatively from potentially malignant forms of pancreatic cyst neoplasm, such as mucinous cyst neoplasms (MCNs) or intraductal papillary mucinous neoplasms [3, 4, 8, 15]. However, if an accurate diagnosis of LEC could be reached preoperatively it may be clinically acceptable to adopt a 'watch and wait' approach rather than opting for surgery in the first instance; especially, if the patient remains asymptomatic [8].

Options for investigating these lesions include CT or magnetic resonance imaging, EUS and fine needle aspiration (FNA), and cyst fluid analysis. Imaging may help to guide a diagnosis and is also important to assess the resection potential of the lesion, but LECs cannot be reliably distinguished from other cystic pancreatic lesions on imaging alone as, radiographically, they may appear similar to a pseudocyst or MCN $[3,15]$.

In some cases, it may be possible to make a cytological diagnosis of LEC through the use of EUS-FNA $[9,25,26]$. EUS features suggestive of LEC include a peripancreatic lesion that appears solid, heterogeneous, and well circumscribed [9, 25, 26]. Cytological presence of squamous material and lymphocytes is diagnostic of LEC [9], and EUS-FNA diagnosis has avoided the need for surgical resection in a number of cases $[9,25,26]$. However, the diagnosis can be complicated by contamination of the aspirate with surrounding tissue (such as mucinous or glandular intestinal epithelium), and the fact that the aspirate is often milky or creamy, which can make it difficult to exclude a diagnosis of cystic neoplasm [26]. The suitability of EUS-FNA for individual patients must also be considered - it was deemed inappropriate in the present case due to the patient's tortuous oesophagus.

Cyst fluid analysis can be helpful to distinguish neoplastic from benign cysts, and it has been suggested in the literature that a cyst fluid CEA level $>200 \mathrm{ng} / \mathrm{ml}$ is strongly supportive of a diagnosis of MCN [15]. However, LECs have also been shown to express markedly elevated levels of CEA well above this diagnostic cutoff (as in the present case), as well as carbohydrate antigen 19-9, and thus, cyst fluid analysis cannot reliably distinguish LECs from potentially malignant cystic lesions $[8,15]$.

Surgery is indicated in symptomatic patients and when malignancy cannot be excluded, surgical excision and pathological analysis remain the gold standard for diagnosis of pancreatic LECs $[5,6,7,8]$. Options for surgical management depend in part upon the location of the lesion within the pancreas, the size of the lesion, and the degree of pancreatic and surrounding tissue involvement $[4,6,7]$. Resection by pancreaticoduodenectomy or distal pancreatectomy may be necessary for larger lesions in the head of the pancreas or those encroaching on the spleen $[4,7]$. Cyst enucleation or drainage may be preferable for smaller, well-delineated lesions [4], although diagnosis should be confirmed prior to such a procedure as it would be suboptimal management for other macrocystic neoplasms [6]. 


\section{Conclusion}

LECs are an extremely rare type of benign pancreatic cystic lesion that pose a diagnostic dilemma as they are difficult to distinguish from cystic pancreatic lesions that have malignant potential. Currently, no reliable preoperative diagnostic method exists, although there is evidence that EUS-FNA may be a way forward. Surgery is indicated in symptomatic patients, although 'watchful waiting' may be clinically acceptable in asymptomatic patients if the diagnosis of LEC can be confirmed non-surgically. Cyst enucleation can be considered for uncomplicated lesions with a confirmed diagnosis, but resection remains the definitive treatment when malignancy cannot be excluded.

\section{Statement of Ethics}

The authors have no ethical conflicts to disclose.

\section{Disclosure Statement}

The authors have no conflicts of interest to declare.

\section{References}

1 Brugge WR, Lauwers GY, Sahani D, Fernandez-del Castillo C, Warshaw AL: Cystic neoplasms of the pancreas. N Engl J Med 2004;351:1218-1226.

-2 Lüchtrath H, Schriefers KH:A pancreatic cyst with features of a so-called branchiogenic cyst. Pathologe $1985 ; 6: 217-219$.

-3 Kavuturu S, Sarwani NE, Ruggeiro FM, Deshaies I, Kimchi ET, Kaifi JT, et al: Lymphoepithelial cysts of the pancreas. Can preoperative imaging distinguish this benign lesion from malignant or pre-malignant cystic pancreatic lesions? JOP 2013;14:250-255.

-4 Sewkani A, Purohit D, Singh V, Jain A, Varshney R, Varshney S: Lymphoepithelial cyst of the pancreas: a rare case report and review of literature. Indian J Surg 2010;72:427-432.

5 Osiro S, Rodriguez JR, Tiwari KJ, Rodriguez, II, Mathenge N, Tubbs RS, et al: Is preoperative diagnosis possible? A clinical and radiological review of lymphoepithelial cysts of the pancreas. JOP 2013;14:1520.

6 Adsay NV, Hasteh F, Cheng JD, Bejarano PA, Lauwers GY, Batts KP, et al: Lymphoepithelial cysts of the pancreas: a report of 12 cases and a review of the literature. Mod Pathol 2002;15:492-501.

7 Yanagimoto H, Satoi S, Toyokawa H, Yamamoto T, Hirooka S, Yui R, et al: Laparoscopic distal pancreatectomy for a pancreatic lymphoepithelial cyst: case report and review of literature. JOP 2013;14:664-668.

8 Domen H, Ohara M, Kimura N, Takahashi M, Yamabuki T, Komuro K, et al: Lymphoepithelial cyst of the pancreas. Case Rep Gastroenterol 2012;6:604-611.

-9 Nasr J, Sanders M, Fasanella K, Khalid A, McGrath K: Lymphoepithelial cysts of the pancreas: an EUS case series. Gastrointest Endosc 2008;68:170-173.

10 Ali S, Wilkinson N, Jensen CS, Gerke H: EUS-guided Trucut biopsies may enable the diagnosis of lymphoepithelial cysts of the pancreas. Report of two cases. JOP 2009;10:409-412.

11 Maekawa H, Yoneyama H, Komatsu Y, Orita H, Sakurada M, Sato K, et al: Pancreatic lymphoepithelial cyst with an intracystic papillary projection. Report of a case. JOP 2009;10:694-696.

$\checkmark 12$ Alcalde Quirós MJ, Catellote Caixal M, Feliu Villaro F, Raventos Estelle A, Caro Tarrago A, Vicente Guillen V: Lymphoepithelial cyst of the pancreas mimicking a cystic neoplasm. Rev Esp Enferm Dig 2010;102:63-65.

13 Matrone A, Russo M, Mollica C, Lombardi D, Lombardi G, Maurea S, et al: Lymphoepithelial pancreatic cyst: an atypical benign pancreatic mass presenting with a 'cheerios-like' appearance. JOP 2010;11:170-172. 
14 Nam SJ, Hwang HK, Kim H, Yu JS, Yoon DS, Chung JJ, et al: Lymphoepithelial cysts in the pancreas: MRI of two cases with emphasis of diffusion-weighted imaging characteristics. J Magn Reson Imaging 2010;32:692-696.

15 Raval JS, Zeh HJ, Moser AJ, Lee KK, Sanders MK, Navina S, et al: Pancreatic lymphoepithelial cysts express CEA and can contain mucous cells: potential pitfalls in the preoperative diagnosis. Mod Pathol 2010;23:1467-1476.

16 Toumi Z, Ammori MB, Al-Habba S, Filobbos R, Ammori BJ: Laparoscopic distal pancreatectomy for a large pancreatic lymphoepithelial cyst: a rare entity. Surg Laparosc Endosc Percutan Tech 2010;20:e211-e214.

17 Clemente G, Sarno G, De Rose AM, Giordano M, Ricci R, Vecchio FM, et al: Lymphoepithelial cyst of the pancreas: case report and review of the literature. Acta Gastroenterol Belg 2011;74:343-346.

18 Kudo D, Hashimoto N, Toyoki Y, Narumi S, Hakamada K: Usefulness of in-phase and out-of-phase magnetic resonance imaging for the detection of pancreatic lymphoepithelial cyst Hepatogastroenterology 2011;58:1403-1405.

19 Bédat B, Genevay M, Dumonceau JM, Frossard JL, Forget J, Morel P, et al: Association between lymphoepithelial cysts of the pancreas and HIV infection. Pancreatology 2012;12:61-64.

20 Foley KG, Christian A, Roberts SA: EUS-FNA diagnosis of a pancreatic lymphoepithelial cyst: three-year imaging follow-up. JOP 2012;13:681-683.

21 Kim WH, Lee JY, Park HS, Won HJ, Kim YH, Choi JY, et al: Lymphoepithelial cyst of the pancreas: comparison of CT findings with other pancreatic cystic lesions. Abdom Imaging 2013;38:324-330.

22 Matsumoto K, Kato H, Tomoda T, Sakakihara I, Noma Y, Yamamoto N, et al: Two cases of lymphoepithelial cyst of the pancreas confirmed by contrast-enhanced endoscopic ultrasound. Nihon Shokakibyo Gakkai Zasshi 2013;110:1823-1830.

23 Nakamura M, Nakashima H: Laparoscopic distal pancreatectomy and pancreatoduodenectomy: is it worthwhile? A meta-analysis of laparoscopic pancreatectomy. J Hepatobiliary Pancreat Sci 2013;20:421-428.

24 Sasaki S, Sueyoshi N, Yamaoka Y, Yano Y, Hiroyoshi Y, Yoshinaka H, et al: Case with gradually enlarging lymphoepithelial cyst of the pancreas that necessitated enucleation. Nihon Shokakibyo Gakkai Zasshi 2014;111:326-333.

-25 Jian B, Kimbrell HZ, Sepulveda A, Yu G: Lymphoepithelial cysts of the pancreas: endosonography-guided fine needle aspiration. Diagn Cytopathol 2008;36:662-665.

26 Karim Z, Walker B, Lam E: Lymphoepithelial cysts of the pancreas: the use of endoscopic ultrasoundguided fine-needle aspiration in diagnosis. Can J Gastroenterol 2010;24:348-350. 


\begin{tabular}{|c|c|c|}
\hline \multirow{2}{*}{$\begin{array}{l}\text { Case Reports in } \\
\text { Gastroenterology }\end{array}$} & \multicolumn{2}{|c|}{ Case Rep Gastroenterol 2016;10:181-192 } \\
\hline & $10.1159 / 000445373$ & $\begin{array}{l}\text { O } 2016 \text { The Author(s). Published by S. Karger AG, Basel } \\
\text { www.karger.com/crg }\end{array}$ \\
\hline
\end{tabular}

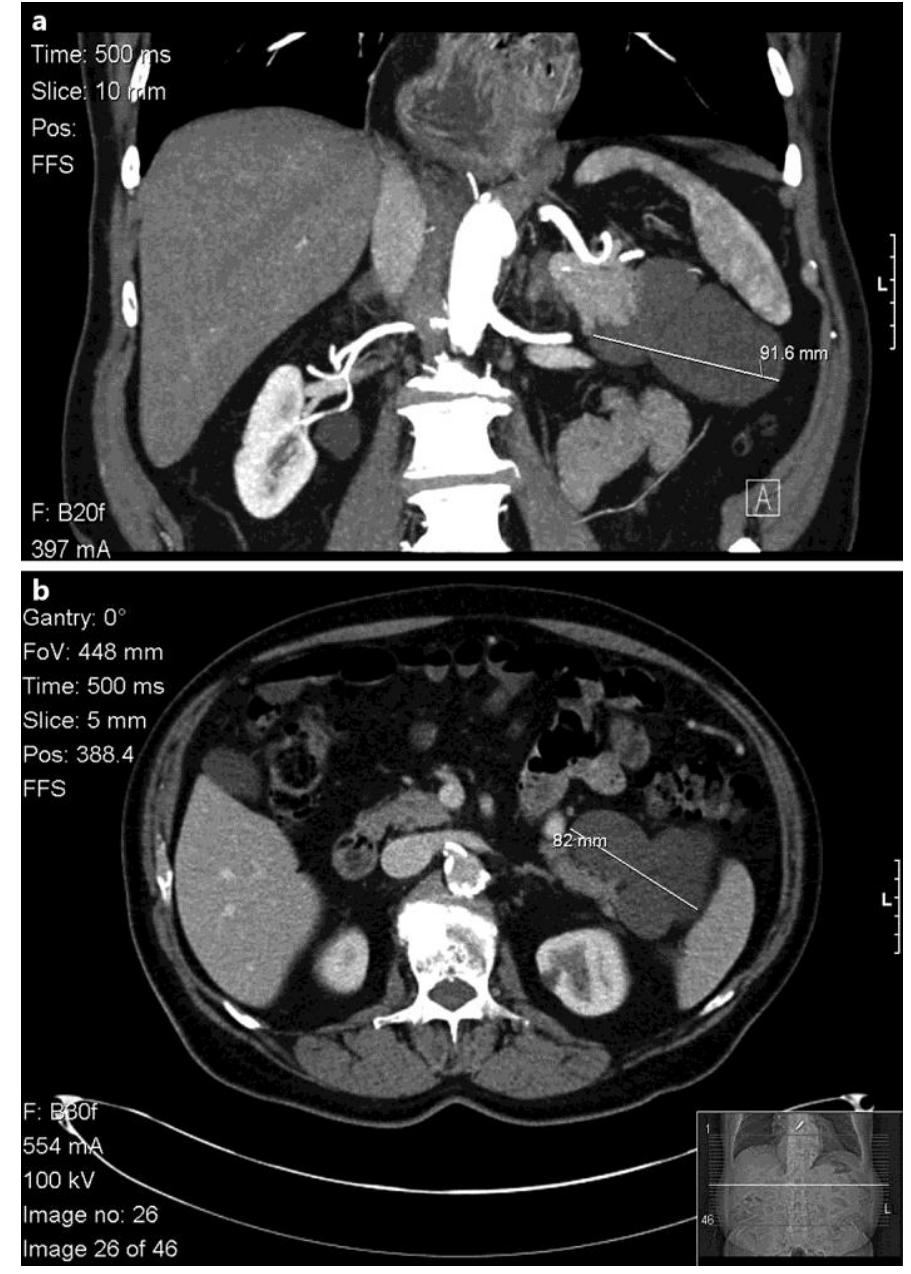

Fig. 1. Coronal (a) and sagittal (b) CT images showing a loculated cystic lesion in the tail of the pancreas closely involving the spleen.
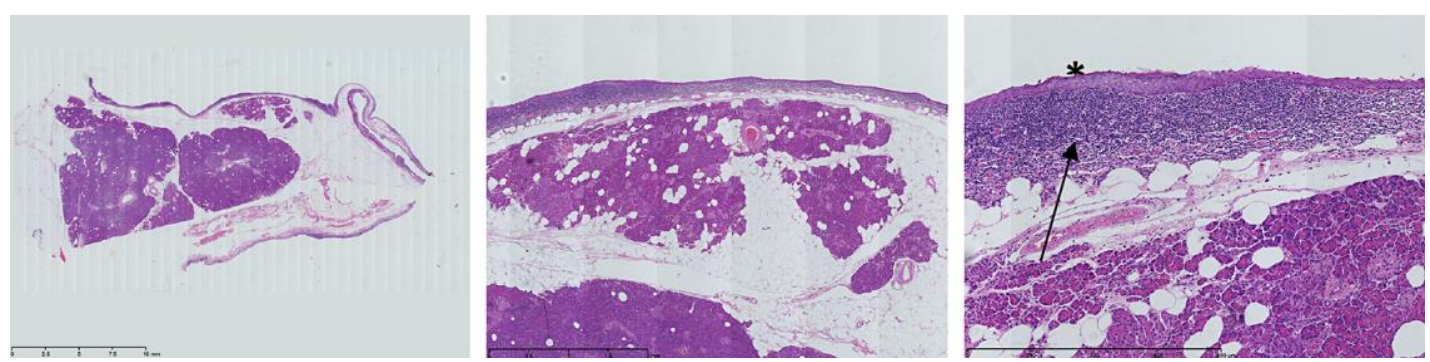

Fig. 2. Histology. Normal underlying pancreas with benign epithelial cyst lining (asterisk) and lymphoid aggregates (arrow) are seen. 
Table 1. Summary of key features of the case reports reviewed by Adsay et al. [6] and Sewkani et al. [4]

Adsay [6], 2002

Cases, $\mathrm{n}$

Sex

Male

Female

Not known/not documented

Mean age, years (range)

Location of LEC in the pancreas

Head

Body

Tail

Not known/not documented

Presentation/symptoms

Abdominal pain/back pain

Gastrointestinal disturbance

Fatigue/weight loss

Asymptomatic/incidental/other unrelated presentation

Not known/not documented

Management

Distal pancreatectomy

Distal pancreatectomy and splenectomy

Enucleation

Local resection

Pancreaticoduodenectomy

Partial pancreatectomy

Resection (unspecified)

Not known/not documented/not applicable

Sewkani [4], 2010

Cases, $\mathrm{n}$

Sex

Male

Female

Not known/not documented

Location of LEC in pancreas 


\section{Case Reports in Gastroenterology}

Case Rep Gastroenterol 2016;10:181-192

(c) 2016 The Author(s). Published by S. Karger AG, Basel www.karger.com/crg

Arumugam et al.: Lymphoepithelial Cyst of the Pancreas

Uncinate

Not known/not documented

Presentation/symptoms

Abdominal pain

Weight loss

Asymptomatic/incidental/other unrelated presentation

Not known/not documented

Management

Conservative

Distal pancreatectomy

Distal pancreatectomy and splenectomy

Enucleation

Pancreaticoduodenectomy

Resection (unspecified) 


\section{Case Reports in Gastroenterology

Table 2. Summary of key features of case reports published since Sewkani et al. [6]

\begin{tabular}{|c|c|c|c|c|c|c|}
\hline $\begin{array}{l}\text { First author [Ref.], } \\
\text { year }\end{array}$ & $\begin{array}{l}\text { Cases, } \\
\mathrm{n}\end{array}$ & Age, years & $\begin{array}{l}\text { Sex } \\
\text { (cases) }\end{array}$ & Presentation/symptoms (cases) & $\begin{array}{l}\text { Location of LEC } \\
\text { in the pancreas } \\
\text { (cases) }\end{array}$ & $\begin{array}{l}\text { Manage- } \\
\text { ment } \\
\text { (cases) }\end{array}$ \\
\hline Jian [25], 2008 & 3 & $47-77$ & M (3) & - & $\mathrm{B}, \mathrm{T}(3)$ & $\begin{array}{l}\mathrm{R}(1) \\
\mathrm{C}(2)\end{array}$ \\
\hline Nasr [9], 2008 & 9 & mean $=51$ & $\begin{array}{l}M(5) \\
F(4)\end{array}$ & - & & $\begin{array}{l}\mathrm{R}(3) \\
\mathrm{C}(6)\end{array}$ \\
\hline Ali [10], 2009 & 2 & $\begin{array}{l}\text { mean }=45 \\
\text { (range 35-54) }\end{array}$ & $M(2)$ & $\begin{array}{l}\text { Periumbilical and RUQ abdominal pain (1) } \\
\text { Vague abdominal pain (1) }\end{array}$ & $\begin{array}{l}\text { B, T (1) } \\
\text { B (1) }\end{array}$ & $\begin{array}{l}\text { DPS (1) } \\
\text { C (1) }\end{array}$ \\
\hline
\end{tabular}

\begin{tabular}{lllllll}
\hline Maekawa [11], 2009 & 1 & 58 & M & Epigastric discomfort, abdominal bloating & - & DP
\end{tabular}

\begin{tabular}{llllllll}
\hline Alcade Quirós [12], & 1 & 73 & M & - & B, T & DPS \\
2010 & & & & &
\end{tabular}

\begin{tabular}{lllllll}
\hline Karim [26], 2010 & 1 & 51 & F & Lower abdominal pain & B, T & C \\
\hline Matrone [13], 2010 & 1 & 63 & M & Asymptomatic, colon cancer follow-up & - & -
\end{tabular}

Nam [14], 2010

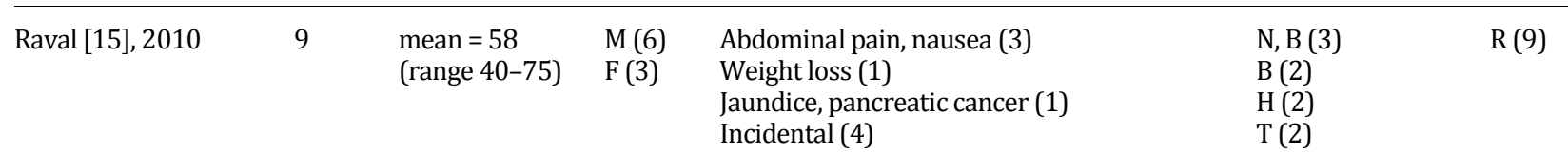

\begin{tabular}{lllllll}
\hline Toumi [16], 2010 & 1 & 43 & M & Upper abdominal pain, $\uparrow$ CA 19-9 & B & DPS
\end{tabular}

Clemente [17], $2011 \quad 1$ 


\section{Case Reports in Gastroenterology}

HIV infection (2)

\begin{tabular}{lllllll}
\hline Domen [5], 2012 & 1 & 60 & M & Upper abdominal discomfort & - & R \\
\hline Foley [20], 2012 & 1 & 58 & M & Left-sided abdominal pain & T & - \\
\hline Kavuturu [3], 2013 & 6 & $\begin{array}{l}\text { mean = 64 } \\
\text { (range 47-76) }\end{array}$ & $\begin{array}{l}\text { M (5) } \\
\text { F (1) }\end{array}$ & $\begin{array}{l}\text { RUQ abdominal pain (4) } \\
\text { Vague abdominal pain and nausea (1) } \\
\text { Incidental (1) }\end{array}$ & $\begin{array}{l}\text { B, H (5) (1) } \\
\text { T (5) }\end{array}$ & $\begin{array}{l}\text { PDD (1) } \\
\text { DP (5) }\end{array}$
\end{tabular}

\begin{tabular}{lllllll}
\hline Kim [21], 2013 & 8 & mean $=55$ & $\begin{array}{l}\text { M (7) } \\
\text { F (1) }\end{array}$ & \\
\hline Matsumoto [22], 2013 & 2 & \multicolumn{7}{c}{ Follow-up care for lung cancer } & B & R \\
\hline Nakamura [23], 2013 & 1 & 67 & M & T & DPS \\
\hline Yanagimoto [7], 2013 & 1 & 53 & M & Incidental & E \\
\hline Sasaki [24], 2014 & 1 & 54 & M & - & T & DPS \\
\hline Current report, & 1 & 79 & M & Abdominal pain & & \\
\hline
\end{tabular}

$\mathrm{B}=$ Body; $\mathrm{C}=$ conservative; $\mathrm{CA}$ = carbohydrate antigen; $\mathrm{DP}=$ distal pancreatectomy; $\mathrm{DPS}$ = distal pancreatectomy and splenectomy; $\mathrm{E}$ = enucleation; $\mathrm{F}$ = female; $\mathrm{H}$ = head; $\mathrm{M}=$ male; $\mathrm{N}=$ neck; $\mathrm{PDD}$ = pancreaticoduodenectomy; $\mathrm{R}$ = resection (unspecified); $\mathrm{RUQ}=$ right upper quadrant; $\mathrm{T}=$ tail. 
Table 3. Key features of LEC of the pancreas identified on review of the world literature

Total cases (including current report)

Sex

Male

Female

Mean age, years (range)

Location of LEC in the pancreas

Tail

Body

Head

Neck

Uncinate

Presentation/symptoms

Abdominal pain/discomfort

Asymptomatic/incidental

Fatigue/weight loss

Gastrointestinal disturbance

Management

Resection

Conservative

Enucleation
148

(C) 2016 The Author(s). Published by S. Karger AG, Basel www.karger.com/crg

Arumugam et al.: Lymphoepithelial Cyst of the Pancreas 